\title{
La foto del mese
}

Paziente di sesso maschile, 62 anni d'età, in dialisi da 22 anni per IRC da tubercolosi renale. Pregresse epatiti B e C post-trasfusionali; epatopatia cronica HCV correlata; fibrillazione atriale cronica; diverticolosi del sigma; broncopneumopatia cronica ostruttiva.

1990 - Comparsa di dolori osteoarticolari, con recrudescenza durante la seduta dialitica ed effetto sintomatico degli steroidi. All'esame radiologico dello scheletro marcata osteopenia senza segni specifici di osteodistrofia uremica, presenza di iniziali segni di osteopatia lacunare cistica alle falangi in sede omerale ( $\mathrm{sn}>\mathrm{dx}$ ) e del cotile dx; normocalcemia ed iperfosforemia con bassi valori di paratormone e fosfatasi alcalina serici, tipici del basso turnover osseo. Grave polineuropatia sensitivo-motoria.

1991 - Intervento per sindrome del tunnel carpale (STC) a sn.

1993 - Collasso di tre corpi vertebrali dorsali.

1994 - Intervento per STC a dx.

1996 - Malessere generale, febbre, astenia, dimagrimento, anemizzazione progressiva e persistente, artropatia acuta alle grosse articolazioni (spalle, anche, ginocchia) e versamento spalla sx; PCR 16 mg\%, immunofluorescenza serica negativa con aumento policlonale delle IgG (pz HCV+); markers tumorali sierologici e sangue occulto nelle feci negativi; non evidenza di processi neoplastici agli esami strumentali (TC addome, ecoaddome, rx-clisma-opa$\mathrm{CO})$.

1997 - Peggioramento del quadro sintomatico della osteoartropatia cronica con versamento alla spalla sn più volte sottoposto a drenaggio evacuativo (Rivalta +++, proteine 55 mg\%, LDH 265 U/, B2-m 37.8 mg\%, granulociti a tappeto, colture per germi comuni e B.K. neg.).

Alla TC diretta della spalla sn: tumefazione ed ispessimento dei tessuti molli periarticolari $(\rightarrow \Rightarrow$ )con presenza di raccolta a sede posteriore. Evidenti lacune ossee marginali a contorni ben definiti $(\rightarrow$ ) nella testa omerale, nella glena ed a livello dell'acromion, sullo sfondo di un diffuso quadro osteopenico.

L'andamento dei valori serici di B2-microglobulina è riportato in tabella.

\begin{tabular}{|llllllll|}
\hline Data & 1991 & 1992 & 1993 & 1994 & 1995 & 1996 & 1997 \\
B2-m (mg\%) & 55,1 & 35,4 & 48,8 & 36,9 & 36,9 & 37,0 & 39,4 \\
\hline
\end{tabular}



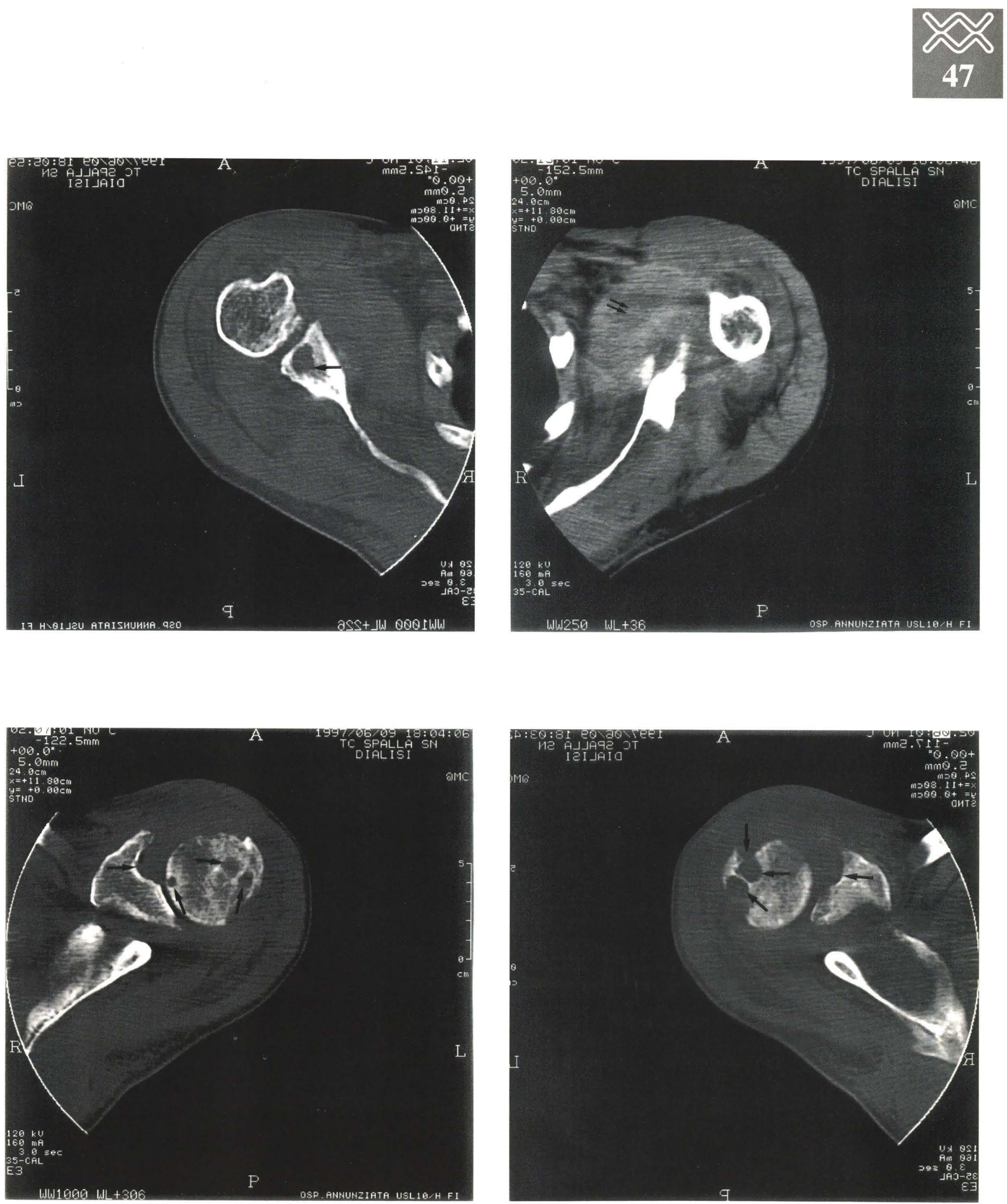

M. Lombardi ${ }^{1}$, S. Michelassil , F. Bausi ${ }^{2}$, A. Taddei

UU.OO. 'Nefrologia e Dialisi, e ${ }^{2}$ Radiologia,

Ospedale SM Annunziata, Azienda USL 10 - Firenze 